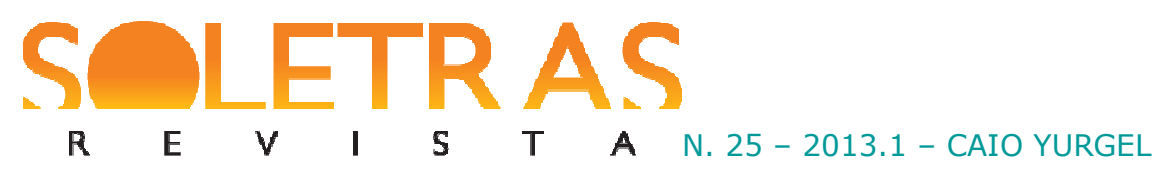

\title{
O realismo literário e a síntese de Bernardo Carvalho
}

Caio Yurgel ${ }^{1}$

Resumo: O presente artigo tem por objeto, em um primeiro momento, organizar um breve panorama do realismo literário e de seus desdobramentos na produção literária contemporânea. Com base nas reflexões de Jonathan Franzen e Tom Wolfe, de um lado, e de Roland Barthes e Maurice Blanchot, de outro, o trabalho visa a situar as 'qualidades' e os 'defeitos' do realismo literário, tais quais percebidos pelos autores elencados. Em um segundo momento, busca-se demonstrar de que maneiras o escritor carioca Bernardo Carvalho através de sua coletânea de crônicas intitulada $O$ mundo fora dos eixos (2005) - propõe uma síntese dessa discussão franco-saxã a partir da margem sul do Atlântico.

Palavras-chave: Realismo. Literatura contemporânea. Bernardo Carvalho.

\section{Considerações iniciais}

O mundo fora dos eixos (2005), obra pouco explorada de Bernardo Carvalho, reúne resenhas e ficções publicadas no jornal Folha de São Paulo no período entre 1995 e 2005 . O presente artigo foca-se apenas nas resenhas, as quais frequentemente partem da análise de obras alheias - um livro, uma exposição, um filme - para, aos poucos, converterem-se em exercícios ensaísticos executados com habilidade pelo escritor carioca. Dentre os muitos temas abordados pelo autor - as intersecções entre ética e estética, os impasses encontrados pela arte contemporânea, os problemas da construção de uma identidade -, destaca-se a recorrente discussão acerca do realismo literário, um tema caríssimo a Bernardo Carvalho e fundamental à compreensão de sua produção ficcional.

Pretende-se, aqui, recuperar e aprofundar parte do referencial teórico mencionado pelo escritor em suas resenhas (Maurice Blanchot, Jonathan Franzen, Harold Rosenberg), de modo a estender-se uma teia mais ampla de significações que contribua à discussão do realismo literário, sobretudo tal qual compreendido fora do eixo Hemisfério Norte. Desse modo, recorre-se não apenas aos textos dos autores mencionados, como também a escritores que lhes são complementares (Roland Barthes, Tom Wolfe, Georges Perec) e que, em seu conjunto,

\footnotetext{
${ }^{1}$ Caio Yurgel é graduado em Filosofia e mestre em Teoria da Literatura / Escrita Criativa, ambos pela PUC-RS. Atualmente, é bolsista do programa Wertewelten da Faculdade de Letras da Universidade de Tübingen (Alemanha). E-mail: caio.yurgel@gmail.com. 
desenham um panorama diverso das implicações do realismo na literatura contemporânea com especial ênfase no âmbito da obra de Bernardo Carvalho.

O avião supersônico Concorde e o realismo literário possuem duas coisas em comum: ambos são invenções franco-britânicas e ambos foram irreversivelmente abalados pelos atentados de 11 de setembro. Embora os franceses possam contestar a primeira afirmação e exigir todo o crédito para a trinca Stendhal-Balzac-Flaubert, é seguro conceder que o realismo seja herdeiro tanto de Malthus quanto de Montesquieu.

O orgulho nacional francês não impediu, porém, que tenha sido a partir do mundo anglo-saxão que o realismo prosperou em escala global, assumindo - entre altos e baixos seu papel de modelo literário alfa. Sintomaticamente, basta sacudir uma dessas colônias norteamericanas de escritores para dela despencarem dúzias de neo-realistas convictos e um pouco abaratados debaixo da claridade do sol - ao passo que, na França, afora a presença massiva de Michel Houllebecq ${ }^{2}$, o realismo tem preferido por esses dias os consolos do anonimato e de um maço de cigarros Gitanes. Muito pode o realismo aprender com a trajetória do rococó: gestado pela França e depois deixado de lado, ele agora se limita a enfeitar as fachadas beges de seu glorioso passado.

Não surpreende que os partidários anglo-saxões do realismo culpem a França pela turbulência enfrentada pelo modelo realista na segunda metade do século 20 (em realidade, nunca surpreende ver um anglo-saxão culpando um francês, nem vice-versa). Segundo eles, a França jogou baixo com o advento do Nouveau Roman e suas desilusões estilísticas e, não satisfeita, ainda tentou cooptar inocentes almas literárias via OuLiPo e seu ardil manifesto Pour une littérature réaliste. Assinado por Georges Perec, o texto argumentava em prol de um realismo que exprimisse "a mais total das realidades concretas", apenas para depois admitir não se tratar essa da mais "ortodoxa e literal das definições” (PEREC, 1992, p. 51). Embora refutasse a esterilidade do 'eu' presente no Nouveau Roman, Perec, em última análise, manipulava o termo 'realismo' e fazia dele uma armadilha concebida não para conduzir à realidade, mas sim ao simulacro e ao jogo auto-referencial. A França provia de combustível as vanguardas e os pós-modernismos, enquanto do outro lado do canal da Mancha e do oceano Atlântico, os adeptos do realismo cobriam os ouvidos no aguardo da inevitável explosão.

\footnotetext{
${ }^{2}$ Convém também mencionar as menos centrais presenças de Benoît Duteurtre, Philippe Lafitte e François Taillandier, para citar alguns. 
Era contra a árida redução da literatura a um mero exercício de estilo ou a um “sublime jogo literário" (WOLFE, 1989, p. 48) que tais adeptos se insurgiam. O escritor e jornalista norte-americano Tom Wolfe foi um dos mais veementes opositores desta literatura que tinha se esquecido da cidade e do engajamento social e optado ao invés por uma anestesia minimalista dos sentidos. Em seu manifesto "Stalking the billion-footed beast: a literary manifesto for the new social novel" (1989), Wolfe culpa o chique europeu pela morte do romance realista, um chique europeu simultaneamente marxista e elitista: marxista porque entendia o romance realista como intimamente ligado à burguesia industrial do século 19, e, portanto, tornado inútil diante da crise dessa mesma burguesia e da dissolução do obsoleto sistema de classes vigente; e elitista porque não considerava o modelo realista suficientemente refinado - um produto de segunda classe quando comparado ao romance psicológico tão incensado pelos franceses (WOLFE, 1989, p. 47).

Segundo Wolfe, foi justamente o realismo que dotou a literatura de imersão, da imprescindível capacidade de prender o leitor às páginas do livro - o realismo significou para a literatura o que a eletricidade significou para a engenharia, e ignorar esse avanço equivaleria a tentar desenvolver uma máquina sofisticada sem, porém, levar a eletricidade em consideração, argumentando que ela já teria sido utilizada "ad nauseam por cem anos" (WOLFE, 1989, p. 51). Pelo contrário: apenas o realismo, o romance social, poderia "retratar o indivíduo em íntima e inseparável relação com a sociedade ao seu redor” (WOLFE, 1989, p. $50)$.

Argumento semelhante é advogado pelo também escritor e também norte-americano Jonathan Franzen, em larga medida responsável pelo resgate de um realismo social tributário de Tolstoi e do romance de costumes. Embora Franzen não concorde plenamente com o manifesto de Wolfe e questione sua leitura da produção literária realista entre os anos de 1960 e 1989 (FRANZEN, 2003, p. 67), ele de todos os modos concorre que a literatura deva conectar “o pessoal ao social” (FRANZEN, 2003, p. 58). Será apenas abarcando uma variedade de experiências tão amplas e dinâmicas quanto a vida de uma cidade (em oposição ao recuo quietista no self e no poético), que a literatura poderá preservar "a tradição de uma linguagem precisa e expressiva, o hábito de se olhar além da superfície e em direção ao interior, e talvez uma compreensão entre experiência privada e contexto público ao mesmo tempo distinta e interpenetrante" (FRANZEN, 2003, p. 90). 
Franzen batiza o renascimento do realismo de realismo trágico ${ }^{3}$ - um trágico que ele deriva de Nietzsche: "um insight anárquico e dionisíaco da escuridão e da imprevisibilidade que se casa com uma claridade apolínea e com a beleza da forma, de modo a produzir uma experiência que é religiosa em sua intensidade" (FRANZEN, 2003, p. 91). No sentido defendido pelo autor americano, o realismo trágico preserva o acesso à sujeira que se oculta por detrás de nossos sonhos ocidentais - e, sobretudo, dos sonhos americanos de nação escolhida, de povo abençoado pelo capitalismo de nossos dias -, preserva o acesso à dificuldade que se oculta por detrás das facilidades tecnológicas, preserva o acesso ao pesar [sorrow] que se oculta por detrás da "narcose pop-cultural": em suma, ele preserva o acesso a todos os presságios que se esgueiram nas margens de nossas existências (FRANZEN, 2003, p. 92).

O realismo trágico parece, assim, "exigir a crença na possibilidade de uma cura" (FRANZEN, 2003, p. 93), uma cura que passa pela compreensão do lugar que o escritor ocupa no mundo: "Sem essa compreensão - sem esse sentimento de pertença ao mundo real seria impossível prosperar em um mundo ficcional" (FRANZEN, 2003, p. 94). O realismo trágico vê um fiapo de esperança onde antes havia apenas fragmentação, caos, aleatoriedade e jogos pós-modernos: "O realismo trágico tem o perverso poder de converter seus adeptos em otimistas qualificados" (FRANZEN, 2003, p. 94), nem que seja pelo simples fato de se poder afirmar: eu faço parte desse mundo. O realismo trágico não almeja mais do que apenas isto: garantir ao leitor e ao escritor (ou seja: à literatura) um lugar no mundo, um sentimento de pertença, uma comunidade imaginária.

Por isso, para Franzen, o conteúdo vem antes da forma: porque, em contato com a literatura, não é uma região lateral do cérebro que é inundada por infinitas associações eroticamente prazerosas sobre a riqueza metafórica e linguística do texto, mas sim o estômago de uma experiência coerente e mortalmente pertinente (FRANZEN, 2003, p. 74). É por esse motivo que Franzen não encontra consolo nem auxílio nos pós-estruturalistas franceses e em sua "celebração filosoficamente incontestável [unassailable] do "prazer do texto"” (FRANZEN, 2003, p. 74). Franzen deseja mais carne e osso ali onde os franceses estão dispostos a fornecer alma e poesia.

\footnotetext{
${ }^{3}$ É digno de nota que o renascimento do realismo não veio sem seus muitos rótulos e subcategorias. O crítico literário americano James Wood, por exemplo, propôs o algo depreciativo realismo histérico; a escritora inglesa Zadie Smith rebateu com o realismo lírico; e mesmo o recente vencedor do Prêmio Nobel de 2012, o chinês Mo Yan, foi laureado pela academia sueca devido ao realismo alucinatório de suas narrativas. 
Roland Barthes, pai do prazer do texto e grande admirador dos paradoxos poéticos, alicerçou boa parte de sua teoria literária no entendimento do real como um exemplo do irreal que forçosamente permeia e define a literatura (um artifício digno de Perec):

Eu dizia há pouco, a respeito do saber, que a literatura é categoricamente realista, na medida em que ela sempre tem o real por objetivo de desejo; e direi agora, sem me contradizer, porque emprego a palavra em sua acepção familiar, que ela é também obstinadamente: irrealista; ela acredita sensato o desejo do impossível (BARTHES, 1989, p. 23).

Mesmo um leitor ocasional da obra de Barthes notará que o realismo lhe serve como um grande saco de pancadas teórico (embora também seja verdade que cada um de seus socos é tão belamente formulado que o leitor, por mais fervoroso adepto do realismo que seja, se descobre em igual medida masoquista). Em O rumor da língua, por exemplo, Barthes acusa o golpe dos autores realistas: apesar de professarem fé no uso de gírias e na exposição de um contexto social transitório, tais autores delegam a tarefa às personagens secundárias - ao passo que "o herói continua a falar uma linguagem intemporal, cuja 'transparência' e neutralidade são supostamente adequadas à universalidade psicológica da alma humana" (BARTHES, 1984, p. 92). Barthes está no encalço do calcanhar de Aquiles do realismo: o receio do esquecimento, o pânico diante do rolo compressor da história. Pois, ao colar-se na descrição de um presente imediato, o realismo coloca sua literatura e sua sorte nas mãos da passagem do tempo: acaso saiam de moda as gírias, acaso o contexto social não mais diga respeito a uma realidade observável, o realismo não terá alternativa a não ser o esquecimento ou uma vida em notas de rodapé. Motivo pelo qual Ernest Hemingway instava a todo jovem futuro escritor a não usar gírias nem termos que não existissem "há pelo menos mil anos", pois apodreceriam em pouco tempo (apud PHILLIPS, 2004, p. 82). Todo escritor realista desconfia mais ou menos de tudo o que é póstumo, porém apenas na medida em que isso não macule seu ego de escritor vivo.

Apodreça ou não a gíria, desde sua primeira grande obra, O grau zero da escrita, Barthes já identificava na literatura realista uma "contradição sem saída":

[...] ou bem o objeto da obra está ingenuamente de acordo com as convenções da forma e, assim, a literatura permanece surda diante da história presente e o mito literário não é ultrapassado; ou bem o escritor reconhece a o vasto frescor [fraîcheur] do mundo presente, mas para dar conta dele ele não dispõe de nada além de uma língua esplêndida e morta diante da página em branco... (BARTHES, 1972, p. 66). 
Posto contra a parede literária, o escritor não pode senão observar uma "disparidade trágica entre o que ele faz e o que ele vê", e é precisamente a partir desse impasse, da busca de um estilo ou mesmo de um não-estilo, da busca de uma neutralidade inocente (barthesianemente compreendida, é claro), que nasce o grau zero da escrita (BARTHES, 1972, p. 67). Contudo, antes de chegar ao grau zero - essa "ausência que significa" (BARTHES, 2003, p. 81) -, Barthes precisa esterilizar a ameaça realista: "uma sub-escrita, derivada de Flaubert, mas adaptada aos desígnios da escola naturalista” (BARTHES, 1972, p. 53); “a escrita realista está longe de ser neutra; ela está, pelo contrário, carregada dos signos mais espetaculares da fabricação [e do artifício]" (BARTHES, 1972, p. 53); "a escrita realista jamais poderá convencer; ela está condenada a somente descrever [e acomodar os signos]" (BARTHES, 1972, p. 54); “a Literatura [...] vai encontrar na escrita artístico-realista - dentro da qual se produzirá boa parte dos romances comerciais - a imagem privilegiada de uma Literatura que possui todos os signos luminosos e inteligíveis de sua identidade" (BARTHES, 1972, p. 54); “nela, a função do escritor não é tanto a de criar uma obra, mas de fornecer uma Literatura que se veja de longe" (BARTHES, 1972, p. 55).

Ou seja: para Barthes, a literatura realista promove a perda do encantamento em prol da descrição; se pretende 'imanente' à realidade objetiva, embora se trate de um modelo altamente fabricado e artificial; e acomoda passivamente a compreensão do que possa ser 'literatura' (o que é ruim - Barthes, inclusive, não consegue evitar a tentação, em O grau zero da escrita, de escrever Literatura com L maiúsculo; e, ao fazê-lo, ele dá mais um indício de sua aposta na perenidade das formas e não na transitoriedade dos conteúdos).

Barthes retoma com frequência o núcleo duro de sua crítica ao realismo em entrevistas, e o faz de maneira lúcida e pertinente, como é o caso deste depoimento reunido no volume Crítica e verdade:

Até o presente, o realismo se definiu muito mais por seus conteúdos do que por sua técnica (a não ser a dos "cadernos de anotações"); o real foi primeiramente o prosaico, o trivial, o baixo; depois, de modo mais largo, a infra-estrutura suposta da sociedade, liberada de suas sublimações e de seus álibis; não se punha em dúvida que a literatura copiasse simplesmente alguma coisa; segundo o nível dessa qualquer coisa, a obra era realista ou irrealista.

Entretanto, o que é o real? Não o conhecemos nunca senão sob forma de efeitos (mundo físico), de funções (mundo social) ou de fantasmas (mundo cultural); em suma, o real nunca é ele próprio mais do que uma inferência; quando se declara copiar o real, isto quer dizer que se escolhe tal inferência e 
não tal outra: o realismo está, em seu próprio nascimento, submetido à responsabilidade de uma escolha; esta é uma primeira má distribuição, própria a todas as artes realistas, precisamente quando se supõe que elas têm uma verdade de certa forma mais bruta e mais indiscutível do que a das outras artes, ditas de interpretação. Existe uma segunda, própria da literatura, e que torna o realismo literário ainda mais mítico: a literatura é apenas linguagem, seu ser está na linguagem; ora, a linguagem já é, anteriormente a todo tratamento literário, um sistema de sentido: antes mesmo de ser literatura, ele implica particularidade das substâncias (as palavras), descontínuo, seleção, categorização, lógica especial (BARTHES, 1982, p. 78-79).

E é aqui que Barthes fecha o círculo e o cerco ao realismo: ao se constituir a partir de uma linguagem já pré-existente, a literatura se deita em uma cama de "sobre-significação" que faz dela (da literatura, não da cama), inescapavelmente, "a própria consciência do irreal da linguagem". Assim,

[...] a literatura mais "verdadeira" é aquela que se sabe a mais irreal, na medida em que ela se sabe essencialmente linguagem, é aquela procura de um estado intermediário entre as coisas e as palavras, é aquela tensão de uma consciência que é ao mesmo tempo levada e limitada pelas palavras, que dispõe através delas de um poder ao mesmo tempo absoluto e improvável. $\mathrm{O}$ realismo, aqui, não pode portanto ser a cópia das coisas, mas o conhecimento da linguagem; a obra mais "realista" não será a que "pinta" a realidade mas a que, servindo-se do mundo como conteúdo (esse próprio conteúdo é aliás estranho à sua estrutura, isto é, a seu ser), explorará o mais profundamente possível a realidade irreal da linguagem. (BARTHES, 1982, p. 79)

A realidade irreal da linguagem. Não se poderia fechar o círculo em uma nota mais barthesiana em sua reverberação poética, em sua recusa ao tedioso trabalho da descrição. Maurice Blanchot não poderia ter feito melhor, embora ele tenha meandrado por essas mesmas linhas:

Outrora André Breton reprovou os romancistas com uma queda pela descrição por desejar interessar-nos pelo amarelo do papel de parede do quarto, pelo piso de ladrilhos branco e preto, pelos armários, pelas cortinas, detalhes fastidiosos. É verdade, tais descrições são tediosas; não há leitor que não as pule, contente no entanto por elas estarem ali, precisamente para serem deixadas para trás (BLANCHOT, 2008, p. 219).

Porque Blanchot não está interessado na descrição e no duro da realidade, mas sim no infinito e no silêncio, na capacidade que a narrativa possui de presentificar aquilo que está ausente. Blanchot ecoa Barthes (e Barthes ecoa Blanchot) ao acusar o realismo de acomodar a 
compreensão do fenômeno literário, de "estabilizá-lo e acalmá-lo" (BLANCHOT, 2008, p. 148) - uma tarefa em tudo vã diante de um mundo que se apresenta em constante movimento e do qual a literatura não pode pretender dar conta: "a arte não é mais capaz de portar a necessidade do absoluto" (BLANCHOT, 2008, p. 265).

É nesse sentido que Bernardo Carvalho saúda Blanchot na condição de um ser de "outro tempo [e] de um mundo mais inteligente e interessante, onde ainda era possível dizer, sem provocar maiores indignações ou comoções populistas, que a verdade da literatura vem da diferença e da estranheza, nunca da adequação às convenções e às demandas" (CARVALHO, 2005, p. 212). A literatura não estabiliza: ela perturba e desacomoda; ela não responde: ela critica e pergunta. Ela deve refutar "as convenções da linguagem da comunicação e do diálogo cotidiano" que o registro discursivo tenta encobrir (CARVALHO, 2005, p. 212):

\footnotetext{
O que interessa na literatura não é a expressão de uma interioridade, ou o mundo subjetivo do autor, muito menos o texto que pretende dar uma visão da realidade, mas a capacidade que a palavra literária tem de escapar desses vícios da linguagem que impedem o homem de confrontar a sua verdadeira condição e morte (CARVALHO, 2005, p. 212-213).
}

Carvalho enxerga nesse "movimento sem fim" (CARVALHO, 2005, p. 213) que é a literatura preconizada por Blanchot - "A literatura vai em direção a ela mesma, em direção à sua essência, que é o desaparecimento" (BLANCHOT, 2008, p. 265) - o espaço errante a partir do qual o escritor tentaria escapar de todo lugar-comum. Não será, portanto, através do realismo e das "convenções da linguagem" (CARVALHO, 2005, p. 212) que a literatura poderá "reter em si uma parte da condição humana" (CARVALHO, 2005, p. 213) - pelo contrário: caberá à literatura "afirmar seu próprio vazio, a sua descontinuidade, os paradoxos e contradições que a linguagem de uso corrente tenta excluir e dissimular" (CARVALHO, 2005, p. 213). Embora rejeite com veemência o realismo, Carvalho nota com perspicácia que “o pensamento de Blanchot pôs a literatura diante de um beco sem saída", engendrando uma "subliteratura automática, fraca, ensimesmada" (CARVALHO, 2005, p. 214). A obra de Bernardo Carvalho é, antes de qualquer coisa, a consciência desse impasse e a busca por uma síntese. Por intermédio de suas incisivas e precisas crônicas publicadas na Folha de São Paulo entre 1995 e 2001 e reunidas no volume $O$ mundo fora dos eixos (2005), Bernardo Carvalho revigora a discussão ao distanciá-la da polaridade franco-britânica e abordá-la a partir da perspectiva do Atlântico Sul. 


\section{“Sobre o que é seu livro, Mr. Joyce?' 'Não é sobre coisa alguma, madame, ele é a coisa""}

O fantasma de Blanchot assombra Bernardo Carvalho. Em ambos transparece a convicção de que não é o destino que importa, mas o trajeto. Carvalho não cansa de repeti-lo de forma mais ou menos explícita: "O que importa é menos o objeto final do que a problemática e as questões levantadas pela sua criação" (CARVALHO, 2005, p. 154). Porém - e este é um dos motivos que fazem de Bernardo Carvalho um escritor tão instigante -, ele evita propor tal conclusão de forma monocromática ou bidimensional; pelo contrário, ele antes integra a literatura ao campo mais amplo das artes visuais, para só então buscar uma síntese que seja nuançada e compatível com ambas formas de expressão. Assim, em nada surpreende vê-lo afirmar que "a luz e a textura podem ser tão ou mais importantes do que os objetos fotografados" (CARVALHO, 2005, p. 160), ou que "a fotografia liberou a pintura da busca de um falso realismo, 'psicológico' e não estético, que a assombrava desde sempre" (CARVALHO, 2005, p. 73). Tampouco surpreende que Carvalho alinhe-se tão plenamente ao crítico de arte americano Harold Rosenberg, para quem "onde não há reflexão sobre o papel da arte também não pode haver arte" (CARVALHO, 2005, p. 153) - o que importa são as questões levantadas no processo.

Em seu Objeto ansioso, Rosenberg argumenta que

[...] a ansiedade se impôs à arte junto com a experiência que acompanha a rejeição de soluções superficiais ou fraudulentas, e que ela surge "não como um reflexo da condição dos artistas, mas como resultado da reflexão que eles fazem sobre o papel da arte entre outras atividades humanas" (ROSENBERG, 2004, p. 19).

As consequências de tal movimento ansioso ao processo de criação artística são lucidamente expostas por Bernardo Carvalho, e se encontram na raiz de sua postura enquanto escritor e crítico:

Reflexão, ansiedade, criação e ação têm a ver antes de mais nada com uma consciência histórica por parte do artista. É a consciência da sua realidade em contraponto com a de outros artistas e movimentos históricos que o faz pôr em questão a sua própria criação. Só essa instabilidade permite que ela possa vir a ser arte. Não existe arte estabelecida ou inquestionável no presente. Acatar o que manda a sua época, evitando o questionamento e o 


\section{SOLETR AS \\ R E V I}

$\begin{array}{llll}\text { S } & \text { T } & \text { A } & \text { N. } 25-2013.1-\text { CAIO YURGEL }\end{array}$

debate, também não seria um ato propriamente artístico. Ou é arte ou é inquestionável. Não dá para ser os dois (CARVALHO, 2005, p. 154).

A questionabilidade da arte a conduz, inevitavelmente, a um espaço de tolerância. Um espaço que - porque há perversos - pode ser confundido com uma espécie de vale-tudo no qual tudo é arte e nada é arte. Carvalho está ciente desse risco - o próprio título da crônica na qual ele analisa o livro de Rosenberg (Será arte?) já indica essa preocupação de fundo. E mais: essa tolerância está intimamente ligada à arte dos anos 90, e convém relembrar que as crônicas reunidas em $O$ mundo fora dos eixos cobrem justamente o período entre 1995 e 2005.

Os artistas da década de 90 quiseram testar a elasticidade do campo artístico, ver quanta pressão ele resistiria antes de romper. Os significados ampliaram-se vertiginosamente à medida que a transdisciplinariedade tornava-se a norma, e isto em resposta aos impasses que a arte não conseguia resolver. A arte, confrontada com a pergunta pela natureza da arte, foi buscar refúgio e soluções tanto em disciplinas humanistas, quanto na arquitetura, na matemática e até mesmo na biologia e na botânica. A fragilização das fronteiras abriu, então, caminho para uma crescente tolerância estética, para a aceitação da impossibilidade contemporânea da obra-prima. Passava interessar menos o objeto final e mais o procedimento intermediário, os caminhos da criação, as soluções e os artifícios. A palavra 'poética' entrou na moda. Em alguns casos, o próprio gesto já era a obra.

O pensamento de Bernardo Carvalho está, sem dúvida, marcado pela vivência dessa década, pela postulação da centralidade do artifício no processo de criação artística: "Hoje, na cultura brasileira, há uma tendência cada vez mais unívoca de refutar o artifício nas artes, em nome da 'expressão da realidade', como se pudesse haver arte sem artifício" (CARVALHO, 2005, p. 75). Uma cruzada contra o artifício nas artes que produziria, na opinião de Carvalho, "uma ilusão perigosa, pois coloca sob suspeita [...] o fazer artístico" (CARVALHO, 2005, p. 77).

Aqui topamos com a pedra no sapato de Bernardo Carvalho: o realismo e sua obsessão com a verossimilhança psicológica. Ao se postular que arte é artifício, como já insistia Roland Barthes, deve-se logicamente refutar qualquer interpretação que veja na arte uma simples "busca de semelhança" e "ilusão das formas" (CARVALHO, 2005, p. 73). É nesse sentido que Carvalho se insurge contra os "neoconservadores da literatura", capitaneados pelo também já mencionado Jonathan Franzen: 
O romance é o que se faz dele, e as possibilidades são infinitas. Um bom romance não precisa ter necessariamente, como querem Franzen e outros neoconservadores, uma boa história com personagens psicologicamente bem construídos e verossímeis. Pode ser também um livro sem história, em que os personagens são pretexto para o desenho de uma visão de mundo. Cada caso é um caso. [...] O que o consenso neoconservador tenta promover nos Estados Unidos, com o respaldo do mercado e dos lucros, e que tem desdobramentos inevitáveis entre escritores pouco originais de países periféricos como o Brasil, é a celebração do produto em detrimento da criação (CARVALHO, 2005, p. 27).

Bernardo Carvalho tenta chamar atenção para uma fórmula binária concisa e endêmica na literatura brasileira contemporânea: a da ação e do diálogo. A literatura que se vale dessa fórmula acaba por ser uma literatura finalista: dirige todos os seus esforços para o desfecho, descarta tudo o que não é essencial à narrativa. $\mathrm{O}$ artifício some do romance, pois o romance está ocupado demais com sua ilusão de objetividade. Quando, pelo contrário, interromper o ritmo de um texto para notar uma discreta rachadura em sua parede ficcional pode significar dar-lhe outro fôlego, ampliar-lhe seu potencial reflexivo. Pois, como já foi mencionado, a literatura não se justifica no desfecho, mas no trajeto. Ela não deve sucumbir à pressão anglosaxã que exige "personagens psicologicamente verossímeis, 'de carne e osso"” (CARVALHO, 2005, p. 46). Ela precisa se fazer presente, lembrar o leitor de que "a arte é o que não está lá” (CARVALHO, 2005, p. 70), mas sim na busca, nos desvios, no esforço de ultrapassar o lugar-comum.

Através da construção narrativa, da observação atenta do cotidiano, a literatura propõe uma experiência não-exaustiva de mundo, uma que deixa margem para o leitor construir-se ao redor. Quando não há mais espaço para o leitor em um livro, quando o livro passa a ser mero reflexo de pressões comerciais e de comodismos populistas, é porque nele não há mais literatura, há apenas conforto - e, como diria Walter Benjamin, "o conforto isola" (BENJAMIN, 2004, p. 124). O conforto literário assemelha-se a uma sala amplamente iluminada, na qual tudo é exatamente tal qual se apresenta - como informação, ou mero divertimento, e não como narrativa. As coisas estão dadas, e nada resta a fazer senão aceitálas enquanto tal.

Ao discutir o livro $O$ partido das coisas, de Francis Ponge, Carvalho dispara:

Não há narração. Não se trata de mais uma dessas ilusões de realidade 'baseadas numa história real' (como se o real fosse narrativo) cuja demanda parece crescer na mesma proporção do fascínio pelo mundo virtual (CARVALHO, 2005, p. 198). 
E, abordando a (recorrente) obra do escritor austríaco Thomas Bernhard, complementa:

\begin{abstract}
A citação é providencial num tempo em que a imaginação na literatura parece gozar de um desprestígio crescente entre os leitores, mesmo entre os mais cultos. Não é preciso muito esforço para notar que não só os livros jornalísticos e as biografias mas também os romances 'baseados em histórias reais' interessam mais os leitores do que as 'obras da imaginação'. O que prende o leitor a um livro em que há ambigüidade entre realidade e ficção é a realidade e não a ficção. A ficção, para ele, é a parte supérflua (CARVALHO, 2005, p. 122-123).
\end{abstract}

Eis o mal-estar da literatura contemporânea: a ficção passa a ser a parte supérflua. O leitor está mais preocupado em saber se aquilo 'aconteceu de verdade', em identificar as marcas - Coca-Cola, Nike, Flamengo - que o assegurem da fidedignidade da narrativa em relação ao mundo que este leitor habita. Nenhuma fricção, nenhum desconforto. Como se a literatura fosse uma extensão natural - e não construída, cultural - da realidade objetiva e cotidiana, como se a imaginação fosse o preço a se pagar pelos confortos de uma história 'de carne e osso' com começo-meio-fim, introdução-desenvolvimento-conclusão:

Uma das grandes contribuições do austríaco Thomas Bernhard à compreensão da literatura - e contra a prática filistina dos que se gabam da naturalidade de suas frases - foi deixar bem claro, para quem ainda não sabia ou tinha esquecido, que toda manifestação literária é artifício, por mais espontânea ou natural que pareça (CARVALHO, 2005, p. 209).

Não que a literatura deva manter-se alheia à - e apartada da - realidade, porém ela tampouco pode se esquecer do artifício que lhe é constitutivo, um artifício que o realismo deseja ocultar com todas as suas forças e com todos os seus truques. Uma literatura puramente realista falhará em investigar as profundidades da consciência humana, contentando-se ao invés em alçar épicos e panorâmicos voos documentais. Porém, por mais alto que voe o realismo em seu afã de dar conta da realidade, essa águia cruel e arredia que é a realidade voará sempre mais alto, escapará sempre a toda tentativa de captura. A realidade é um animal selvagem que não pode ser domesticado.

É preciso ir contra o seu tempo para alcançá-lo. Ulisses, por exemplo, cria uma 'realidade antecipatória'. Não basta à literatura fazer a ilustração de sua época (ou da ciência de sua época). Não basta observar e descrever a SOLETRAS - Revista do Departamento de Letras da FFP/UERJ 
realidade. Não basta representar a atualidade. É preciso ir além. Forma e conteúdo devem estar integrados (CARVALHO, 2005, p. 90).

A literatura deve ir contra o grão da realidade, deve resistir à pressão do desfecho e da psicologia barata, deve preferir movimento a destino, trajeto a objetivo. Se o realismo entende o artifício como um 'defeito', a literatura - ou ao menos a literatura de Bernardo Carvalho fará do defeito, estilo; tirará "força da sua fragilidade" e reforçará "o que lhe é específico" (CARVALHO, 2005, p. 175). Se não uma síntese, nasce aí ao menos uma esperança.

\section{Referências bibliográficas:}

BARTHES, Roland. Crítica e verdade. São Paulo: Perspectiva, 1982. . Aula. São Paulo: Cultrix, 1989. . Elementos de semiologia. São Paulo: Cultrix, 2003. . Le degré zéro de l'écriture. Paris: Seuil, 1972. . O rumor da língua. Lisboa: Edições 70, 1984.

BENJAMIN, Walter. Obras Escolhidas III: Charles Baudelaire, um lírico no auge do capitalismo. São Paulo: Brasiliense, 2004.

BLANCHOT, Maurice. Le livre à venir. Paris: Éditions Gallimard, 2008.

CARVALHO, Bernardo. O mundo fora dos eixos. São Paulo: Publifolha, 2005.

FRANZEN, Jonathan. How to be alone. Nova York: Picador, 2003.

PEREC, Georges. L.G.: une aventure des années soixante. Paris: Seuil, 1992.

PHILLIPS, Larry W. Ernest Hemingway on writing. New York: Scribner, 2004.

ROSENBERG, Harold. Objeto ansioso. São Paulo: Cosac Naify, 2004.

WOLFE, Tom. Stalking the billion-footed beast: a literary manifesto for the new social novel. In: Harper's Magazine, New York, n. 279, p. 45-56, nov. 1989. 


\title{
Literary realism and the synthesis of Bernardo Carvalho
}

\begin{abstract}
The following article aims at drawing a brief outline both of realism in literature as well as of its repercussions within contemporary fiction. By resorting to the works of Jonathan Franzen and Tom Wolfe, on one hand, and of Roland Barthes and Maurice Blanchot on the other, it seeks to locate the perceived 'qualities' and 'defects' of literary realism according to the above-mentioned thinkers. Furthermore, it seeks to show how Bernardo Carvalho through his collection of chronicles, O mundo fora dos eixos (2005) - synthesizes this AngloFrench discussion from a South American perspective.
\end{abstract}

Key words: Realism. Contemporary fiction. Bernardo Carvalho.

Artigo recebido em: 10 de maio de 2013.

Artigo aprovado em: 24 de junho de 2013. 